\title{
Obesity, adipose tissue function and the role of vitamin $D$
}

\author{
ANETA U. KOSZOWSKA ${ }^{1,2}$, JUSTYNA NOWAK ${ }^{1,2}$, ANNA DITTFELD ${ }^{3}$, ANNA BRONCZYK-PUZOŃ, \\ AGATA KULPOK ${ }^{5}$ BARBARA ZUBELEWICZ-SZKODZINSSKA ${ }^{2}$
}

${ }^{1}$ Doctoral Study in the School of Pharmacy with the Division of Laboratory Medicine in Sosnowiec, Medical University of Silesia in Katowice, Poland

${ }^{2}$ Department of Nutrition-Associated Disease Prevention, Faculty of Public Health, Medical University of Silesia in Katowice, Poland ${ }^{3}$ Doctoral Study in the School of Medicine with the Division of Dentistry in Zabrze, Medical University of Silesia in Katowice, Poland ${ }^{4}$ Doctoral Study in the School of Health Care in Katowice, Medical University of Silesia in Katowice, Poland

${ }_{5}^{5}$ Department of Endocrinology, County Hospital Piekary Śląskie, Poland

\begin{abstract}
Introduction: Obesity is not just a cosmetic problem. Pathological accumulation of body fat can cause many health problems: insulin resistance, impaired glucose tolerance, and diabetes mellitus type 2. It may also increase morbidity and mortality. Adipose tissue plays an important role in body homeostasis by producing and secreting several bioactive proteins known as adipokines: adiponectin, leptin, resistin, visfatin, and apelin, which are involved in the regulation of food intake, glucose and lipid metabolism, and insulin action. There can be observed nutritional deficiencies, despite increased food intake, in morbidly obese people. Data concerning concentrations of serum $25(\mathrm{OH}) D_{3}$ presented an inverse correlation with obesity parameters like: BMI (body mass index), waist circumference, fat mass or percentage of body fat. Also, higher insulin sensitivity was associated with higher concentrations of vitamin $D$.

Conclusions: Studies published up to now suggest that vitamin D plays an important role in adipose tissue function and could be involved in the synthesis and modulation of adipokine production. This article is a review of the literature on fatty tissue function and the role of vitamin $D$ in obesity.
\end{abstract}

Key words: obesity, vitamin D, fatty tissue, adipokines.

(Centr Eur J Immunol 2014; 39 (2): 260-264)

\section{Introduction}

The number of obese people has dramatically increased over the last few years [1]. Obesity is a consequence of pathological accumulation of body fat. It leads to many impairments and increases the risk of morbidity and mortality [2]. Obesity is defined as a multifactorial, chronic disease resulting from a long-term positive energy balance, when genetic and environmental factors are involved [1, 2]. In consequence, excess visceral fat could be the cause of hypertension, prothrombotic and proinflammatory activity, and dyslipidemia [3]. Finding a connection among adipose tissue function, the pathogenesis of obesity, and other health problems associated with overweight could bring many benefits to public health [4]. In the last few years, several studies focused on the role of vitamin D in the prevention of civilization diseases including obesity $[4,5]$. Some of them found connections between vitamin D status and adipokines [4]. The purpose of this article was to review the literature concerning fatty tissue function and vitamin $\mathrm{D}$ in obesity.

\section{Vitamin D metabolism in the human body and the role of vitamin $D$ in bone homeostasis}

Most of the vitamin D requirements are formed in the skin as a result of sufficient sunlight exposure, and the remainder is met by diet $[5,6]$. Ultraviolet $B$ exposure induces vitamin $\mathrm{D}$ biosynthesis in the skin (7-dehydrocholesterol is changed to previtamin $\mathrm{D}_{3}$ form) [4-6]. Next, in the liver, pre-vitamin $\mathrm{D}_{3}$ is hydroxylated into $25(\mathrm{OH}) \mathrm{D}_{3}$. Further, in the kidneys, $1 \alpha$-hydroxylase converts $25(\mathrm{OH})$ $\mathrm{D}_{3}$ into $1,25(\mathrm{OH})_{2} \mathrm{D}_{3}$, which is known as the biologically active metabolite [4-6]. The biologically active form of vitamin $\mathrm{D}$ is $1,25(\mathrm{OH})_{2} \mathrm{D}_{3}$ and it binds the VDR receptor (vitamin D receptor) $[4,7,8]$. Vitamin $\mathrm{D}$ receptor has been found in most human tissues: skin keratinocytes, macrophages, smooth muscles, pancreatic $\beta$-cells, osteoblasts [4]. Kidney synthesis is regulated by the parathormone, concentrations of calcium and phosphorus in serum and many other factors, e.g. FGF-23 (fibroblast growth factor-23) [9]. The active form of vitamin D maintains cal-

Correspondence: Aneta Koszowska, Department of Nutrition-Associated Disease Prevention; Faculty of Public Health, Medical University of Silesia in Katowice, Piekarska 18, 41-902 Bytom, Poland, e-mail: anetakoszowska@op.pl 
cium homeostasis by increasing efficiency of calcium absorption in the intestine and stimulating the differentiation of osteoclasts [7, 10]. Intestinal calcium transport increases by about $45-65 \%$ in women when vitamin $\mathrm{D}$ concentration in blood increases from an average of $20-32 \mathrm{ng} / \mathrm{ml}$ [11]. During childhood, vitamin D deficiencies cause skeletal deformations. In adults, vitamin D deficiencies are responsible for osteopenia, osteoporosis, and an increased risk of bone fractures $[6,11]$. Reasons for deficiency are low vitamin supply from food, insufficient exposure to sunlight, and decreased ability to synthesize vitamin D in the skin. Additionally, many diseases connected with age can cause renal and liver failure, which induces the activation of previtamin $\mathrm{D}[5,12,13]$. The circulating form of vitamin $\mathrm{D}$ is $25(\mathrm{OH}) \mathrm{D}_{3}$, and its serum concentration is commonly used as an indicator of vitamin D status $[4,5,7,8]$. Proper vitamin D serum concentrations are defined differently in many studies, and that causes difficulties in specifying standard concentrations. Most often, vitamin D deficiency is defined as a concentration below $20 \mathrm{ng} / \mathrm{ml}$, and a sufficient concentration is above $30-80 \mathrm{ng} / \mathrm{ml}[5,7,9,11]$. Some authors defined toxic concentrations of $25(\mathrm{OH}) \mathrm{D} 3$ as $150 \mathrm{ng} / \mathrm{ml}$ [5]. According to many studies, deficiencies of this vitamin are prevalent among people from all age groups both in Europe and the United States [11]. Vitamin $\mathrm{D}$ deficiency is still an important epidemiological problem in many countries $[5,7,14]$.

\section{A new role of vitamin $D$}

Adequate vitamin D intake and its status are important not only for bone health and Ca-P (calcium and phosphorus) metabolism but also for optimal functioning of many organs and tissues throughout the body $[4,6,11,15]$. In recent years, a new pleiotropic role of vitamin $D$ has been discovered. Vitamin D affects multiple organs and metabolic processes [4]. Many studies describe the link between vitamin $\mathrm{D}$ deficiencies and cardiovascular risk, diabetes mellitus, hypertension, and dyslipidemia [4, 5, 7, 8, $15,16]$. Lower concentrations of circulating vitamin D were associated with a higher fasting glucose level, reduced insulin sensitivity, and increased risk of type II diabetes mellitus [8, 11, 13, 17]. Moreover, low concentrations of vitamin D were observed in neoplasms, e.g. prostate cancer, colon cancer, breast cancer [5, 6]. Recently, the connection between vitamin $\mathrm{D}$ deficiencies and obesity has been discovered $[4,6]$. Vitamin D receptor regulates about $3 \%$ of the human genome and is also present in immune cells, which can suggest an immunomodulatory effect of vitamin D [18].

\section{Vitamin D, obesity and health problems}

Morbidly obese people may have nutritional deficiencies despite increased food intake [1]. Additionally, obe- sity is often associated with vitamin D deficiency [1, 4]. Serum $25(\mathrm{OH}) \mathrm{D}_{3}$ concentrations described in the studies were inversely correlated with obesity parameters like BMI (body mass index), fat mass or percentage of body fat, and waist circumference $[4,9]$. Clinical and epidemiological studies showed that obese people have lower vitamin D status [4]. Bioavailability could be limited by the sequestration of this vitamin in white adipose tissue $[4,5]$. Some double blind studies with a placebo control group showed that vitamin D and Ca dietary supplementation for 16 weeks reduced visceral fat in overweight and obese adults $[4,19]$. This may prove that vitamin D plays an important role in keeping our body in shape [4]. Impaired insulin action is closely linked with obesity [3, 4]. Adipose tissue releases free fatty acids, hormones and cytokines such as leptin, adiponectin, resistin, TNF- $\alpha$ (tumor necrosis factor $\alpha$ ), and other factors that modify insulin action $[1,4,20]$.

\section{The role of adipose tissue in homeostasis}

Adipose tissue is also called an active endocrine organ [3]. It plays an important role not only in fat storage but also in the production and secretion of several bioactive proteins known as adipokines (adipose tissue hormones) [3, 4, 21, 22]. Adipokines are involved in a number of biological and physiological processes $[3,20]$. They play an important role in body homeostasis influencing food intake, glucose and lipid metabolism, vascular remodeling, and insulin action [3, 21, 23]. The importance of fatty tissue is visible in obesity as well as in malnutrition [3]. A fat-rich diet contributes to the accumulation of adipose tissue, which leads to insulin resistance [1,3]. Additionally, hypertrophy of adipocytes is connected with increased synthesis and secretion of proinflammatory mediators such as: TNF- $\alpha$, IL-6 (interleukin-6), and IL-1 (interleukin-1) [1, 3]. It also leads to increased concentrations of circulating cytokines and promotes adipose tissue inflammation, characterized by macrophages infiltration $[1,4]$. Studies showed that increased secretion of cytokines, such as TNF- $\alpha$, IL- 6 , and reduction of adiponectin are involved in the pathogenesis of obesity [1, 3, 4]. Moreover, a fat-rich diet increases IL-6 concentrations in human adipocytes [1]. Published studies showed that vitamin $\mathrm{D}$ could be involved in adipose tissue functions [4]. Vitamin D and VDR are implicated in preadipocyte differentiation into adipocytes [4].

\section{Adiponectin}

Adiponectin secreted in adipose tissue modulates many metabolic processes, especially carbohydrate and fatty acid metabolism $[3,15]$. It has a protective role in atherosclerosis, diabetes mellitus and inflammation $[3,15]$. Adiponectin reduces TNF- $\alpha$ and IL- 6 production and activity [20]. 
According to published data, hypoadiponectinemia can increase the risk of metabolic syndrome and coronary artery diseases [23]. Secretion of adiponectin increases with body mass reduction and decreases with obesity [3, 21]. The studies showed a positive correlation between adiponectin and HDL (high density lipoprotein) cholesterol and glucose disposal, and negative with blood pressure, fasting glycemia, insulinemia and plasma concentrations of triglycerides and LDL (low density lipoprotein) cholesterol [3]. Adiponectin has a potential diagnostic value as a biomarker of insulin resistance [3]. Additionally, in vitro studies proved that calcium and $1,25(\mathrm{OH})_{2} \mathrm{D}_{3}$ regulate expression of adipokines in visceral fat, which suggests that vitamin D may regulate adiponectin gene expression [15]. It was observed that $1,25(\mathrm{OH})_{2} \mathrm{D}_{3}$ downregulates TNF- $\alpha$ gene, which is one of the factors affecting adiponectin synthesis [15].

In the Gannagé Yared et al. study on a Middle Eastern population of non-obese young people, the concentration of serum $25(\mathrm{OH})$ vitamin $\mathrm{D}_{3}$ was positively correlated with adiponectin levels and HDL cholesterol. Vitamin D was inversely correlated with insulin and the HOMA index (homeostasis models assessment of insulin resistance), BMI, waist circumference, fasting glucose [4, 15]. Hataikarn et al. demonstrated that vitamin D concentrations are positively correlated with adiponectin concentrations and negatively associated with HOMAR- IR and BMI in the group of people with abnormal glucose tolerance. This research indicates the role of adiponectin as a link between insulin resistance and vitamin D status $[11,21]$. Lenchik et al. showed a positive correlation between adiponectin and age and also a negative correlation between adiponectin and WHR (waist hip ratio). It is not significantly associated with BMI, height, weight and waist circumference [24]. But there was observed an inverse association between bone mineral density and adiponectin [24].

\section{Leptin}

Leptin is a circulating hormone produced primarily by adipose tissue $[3,23]$. In humans, the leptin gene (OB) is located on 7 chromosome [3]. Leptin synthesis is stimulated by insulin, glucocorticosteroids, TNF- $\alpha$ and estrogens, and inhibited by free fatty acids and growth hormones [3]. It is secreted into the bloodstream, mainly from adipocytes, and regulates food intake and metabolism $[3,23]$. The concentration of circulating leptin increases with fat mass and decreases with caloric restriction and body mass reduction [3]. Leptin secretion is also regulated by the circadian rhythm. The highest concentration is observed between 22:00 and 3:00, which could explain the reduction of food intake at this time [3]. Leptin is known as the satiety hormone, because it inhibits the synthesis of neuropeptide Y suppressing appetite [3]. Disturbances in leptin secretion cause an increase in appetite $[3,25]$. In addition, leptin has pleiotropic action in organism physiology and behavior regulation. Leptin also regulates bone development, growth and homeostasis, lung development and function, immune function, thyroid function, and stress response $[4,25]$. Several studies prove the relationship between vitamin D concentrations and leptin. Vitamin D powerfully inhibits in vitro leptin secretion by human adipose tissue [17]. The clinical significance of the connections between leptin and vitamin $\mathrm{D}$ remains to be ascertained.

\section{Resistin}

The main role of resistin is to supply glucose during starvation. The pathological effect is connected with the formation of excessive body fat [3]. Resistin impacts inflammation and energy homeostasis [3]. In addition, resistin increases LDL cholesterol concentration and the risk of cardiovascular disease. Some studies showed a positive correlation between resistin and insulin resistance [3]. Vaidya et al. found a positive association between $25 \mathrm{OH} \mathrm{D}$ and plasma resistin concentrations in patients being on high dietary sodium and low dietary sodium. Increasing $25 \mathrm{OH} \mathrm{D}$ status was associated with higher resistin concentrations in both groups [22]. Vitamin D may be involved in resistin regulation through an unknown mechanism. Further studies are required to understand the existing relationship between resistin and vitamin D [22].

\section{Visfatin}

Visfatin, also known as a pre-B cell colony-enhancing factor 1 (PBEF 1), is an adipokine predominantly expressed in visceral adipose tissue and also in human and animal hepatocytes and muscles [26, 27]. Visfatin is an endocrine, autocrine and paracrine peptide which has recently been identified as a new adipokine affecting insulin resistance by a binding insulin receptor [26, 28]. Furthermore, visfatin has been linked to several inflammatory conditions of $\beta$-cell function, and cardiovascular disease [28]. The growing number of publications should provide more information about the relationship between visfatin and vitamin D. Some studies showed an increasing visfatin concentration in obesity [3].

\section{Adipokines and vitamin D}

Vilarrasa et al. showed a negative correlation between plasma $25(\mathrm{OH}) \mathrm{D}_{3}$ and body mass index, body fat, waist and hip circumference, and leptin in the healthy population [10]. No significant associations were found between $25(\mathrm{OH}) \mathrm{D}_{3}$ and plasma concentrations of resistin, interleukin-18 and adiponectin, but patients with vitamin D deficiencies had a higher body mass index, higher leptin 
concentrations, and fat mass percentage compared with patients with adequate levels of $25(\mathrm{OH}) \mathrm{D}_{3}$ [10]. In the same study conducted on a group of morbidly obese patients, the authors did not find differences between vitamin D status and adipokines and inflammatory cytokine concentrations [10]. Additionally, no associations were found between vitamin $\mathrm{D}$ and insulin resistance, lipid profile and plasma glucose [10]. The study did not show any associations between vitamin D concentrations and insulin resistance as well as glucose metabolism in a group of morbidly obese patients [10].

\section{Pro-inflammatory cytokines and vitamin D}

Inflammation plays an important role in the development of chronic diseases such as cardiovascular diseases, metabolic syndrome and diabetes mellitus type $2[1,4$, $27,28]$. Excessive release of pro-inflammatory cytokines can result in dysregulation of glucose and lipid metabolism and vascular function. Pro-inflammatory cytokines may affect adipocytes, muscle tissue, and blood vessels [27]. The potential role of vitamin D in the modulation of inflammation in obesity and other chronic diseases has drawn an increasing interest in recent years [4, 26, 29].

Tumor necrosis factor $\alpha$ is a potent cytokine that plays an important role in the regulation of immune system functions. In fatty tissue, TNF- $\alpha$ inhibits the activity of genes connected with fatty acids and glucose metabolism as well decreases secretion of adiponectin $[1,3]$.

Interleukin 6 is considered a major inflammatory mediator in obesity [1]. Just as TNF- $\alpha$, IL-6 downregulates adiponectin production $[1,3]$. Secretion increases along with adiposity and correlates with body fat percentage and insulin resistance [1]. A high concentration of IL-6 is a risk factor for diabetes mellitus type II and cardiovascular complications [3].

Interleukin $\mathbf{1 0}$ is known as an anti-inflammatory cytokine which antagonizes the action of IL-6 [1]. The role of IL-10 is to increase insulin sensitivity, to protect from obesity-associated macrophage infiltration, and to prevent increases in proinflammatory cytokines [1].

\section{Vitamin D deficiency can cause immune dysregulation}

In some studies, the authors observed that vitamin D deficiency can lead to immune dysregulation, for example defective macrophages function, such as impaired phagocytosis, chemotaxis, and increased production of proinflammatory cytokines [10]. However, the number of these studies is small and focused on the relationship between vitamin D and IL-6, IL-10 and TNF- $\alpha$ [10]. In obesity, there is increased infiltration of fatty tissue by Il-6 and TNF- $\alpha$ secreting macrophages, which augments insulin resistance [3]. Findings suggest that mature adipocytes as well as macrophages are able to take up $25(\mathrm{OH})$ $\mathrm{D}_{3}$, convert it into $1,25(\mathrm{OH})_{2} \mathrm{D}_{3}$, and release the active hormone [4]. However, the connection between adipose tissue macrophages and their potential role in local production of $1,25(\mathrm{OH})_{2} \mathrm{D}_{3}$ has to be clarified [4]. Some results showed that $1,25(\mathrm{OH})_{2} \mathrm{D}_{3}$ has potential immunoregulatory effects by the inhibition of IL-6, IL-8 and $\gamma$ interferon production by the peripheral blood mononuclear cells from psoriatic patients [4]. On the basis of in vivo studies, Lira et al. showed that vitamin D and vitamin E supplementation reduce weight gain in mice on a highfat diet. Additionally, the authors reported a reduction of IL-6 serum concentrations [1]. Chronic inflammation is associated with oxidative stress, which results in an elevated number of reactive molecules such as: reactive oxygen and nitrogen species [27]. Several micronutrients, such as vitamin E, ascorbic acid, and vitamin D, are recognized as antioxidants with anti-inflammatory properties $[1,27]$. In a study on healthy young Canadian adults, Garcia-Bailo et al. found that $\alpha$ tocopherol, but not vitamin $\mathrm{D}$ or ascorbic acid, is inversely associated with inflammation in healthy young adults [27].

\section{Vitamin D and insulin action}

The role of vitamin D in insulin secretion was described in both in vitro and in vivo studies [10]. The results showed that this vitamin is essential for proper insulin release and for maintenance of glucose tolerance $[9-11,15]$. People with vitamin D deficiencies had a higher risk of insulin resistance and metabolic syndrome [9]. Some studies showed that a low serum concentration of $25(\mathrm{OH}) \mathrm{D}_{3}$ was associated with impaired glucose tolerance and diabetes $[30,31]$. The role of vitamin D in type 2 diabetes was considered. Higher insulin sensitivity was usually accompanied by higher concentrations of vitamin D [11]. Abnormal glucose tolerance could indicate a proinflammatory state due to reduced adiponectin levels, probably by the action of proinflammatory cytokines: TNF- $\alpha$, and IL-1 [11]. Vitamin D possesses anti-inflammatory properties and reduces the effect of proinflammatory cytokines on circulating adiponectin [11,21]. Analysis of the results of prospective research of the Nurses' Health Studies underlines the importance of vitamin D and calcium supplementation in the prevention of diabetes mellitus type $2[9,31]$. It was observed that proper supplementation of vitamin D improved the ability of the islets of Langerhans in the conversion from proinsulin to insulin [9]. In a group of patients with renal failure undergoing peritoneal dialysis, the authors observed that vitamin D supplementation therapy significantly decreased PTH (parathyroid hormone) levels and insulin resistance [21]. In diabetes mellitus type 2 with vitamin deficiencies, daily intake of 
yoghurt fortified with vitamin D lead to increased vitamin D concentrations and improved glycemic status [4]. Further clinical studies concerning the role of vitamin D supplementation among patients with diabetes mellitus type 2 are required [11].

\section{Conclusions}

Finding a connection between adipose tissue function, the pathogenesis of obesity and other obesity-related health problems could bring many benefits to public health, especially in the context of vitamin D deficiency [4]. Future investigations are necessary to understand the relationship between vitamin D status, inflammation and regulation of adipokine secretion [10].

\section{References}

1. Lira FS, Rosa JC, Cunha CA, et al. (2011): Supplementing alpha- tocopherol (vitamin E) and vitamin D3 in high hat diet decrease IL-6 production in murine epididymal adipose tissue and 3T3-L1 adipocytes following LPS stimulation. Lipids Health Dis 10:37.

2. Wang Z, Nakayama T (2010): Inflammation, a Link between Obesity and Cardiovascular Disease. Mediators Inflamm ID 535918.

3. Skowrońska B, Fichna M, Fichna P (2005): The role of adipose tissue in endocrine system. Endokrynol Otyłość 1: 21-29.

4. Ding C, Gao D, Wilding J, et al. (2012): Vitamin D signaling in adipose tissue. Br J Nutr 108: 1915-1923.

5. Napiórkowska L, Franek E (2009): Rola oznaczania witaminy D w praktyce klinicznej. Chor Serca Naczyń 6: 203-210.

6. Gowin E, Horst-Sikorska W (2010): A tablespoon of cod liver oil for everyone. Farmacja Współczesna 3: 174-180.

7. Frankiewicz T (2011): Vitamin D supplementation - is it only osteoprotection? Prz Menopauz 4: 328-333.

8. Płudowski P, Kryśkiewicz E, Karczmarewicz E (2012): Zasady suplementacji i standardy oceny zaopatrzenia organizmu w witaminę D w świetle jej działania plejotropowego. Post Nauk Med 3: 265-272.

9. Żukowska-Szczechowska E, Kiszka B (2011): Vitamin D deficiency - diagnosis and management in order to reduce cardiovascular risk in patient with diabetes. Forum Zab Metabol 2: 151-157.

10. Vilarrasa N, Vendrell J, Maravall J, et.al. (2010): Is plasma $25(\mathrm{OH}) \mathrm{D}$ related to adipokines, inflammatory cytokines and insulin resistance in both healthy and morbidly obese population? Endocr 38: 235-242.

11. Nimitphong H, Chanprasertyothin S, Jongjaroenprasert W, Ongphiphadhanakul B (2009): The association between vitamin D status and circulating adiponectin independent of adiposity in subject with abnormal glucose tolerance. Endocor 36: 205-210.

12. Głuszko P (2010): Vitamin D deficiency, cardiovascular diseases and disability in elderly people. Gerontol Pol 2010; 18 : 66-70.

13. Kupisz-Urbańska M, Galus K (2011): Epidemiology of vitamin D deficiency among elderly people - chosen aspects. Gerontol Pol 19: 1-6.
14. Arnson Y, Amital H (2011): Is vitamin D a new therapeutic agent in autoinflammatory and pain syndromes? IMAJ 13: 234-235.

15. Gannagé-Yared MH, Chedid R, Khalifie S, et al. (2009): Vitamin $\mathrm{D}$ in relation to metabolic risk factors, insulin sensitivity and adiponectin in a young Middle- Eastern population. Eur J Endocrinol 160: 965-971.

16. Menendez C, Lage M, Peino R, et.al. (2001): Retinoic acid and vitamin D3 powerfully inhibit in vitro leptin secretion by human adipose tissue. J Endocrinol 170: 425-431.

17. Wasiluk D, Stefanska E, Ostrowska L, et al. (2012): Nutritive value of daily food rations of patients with psoriasis vulgaris: a preliminary report. Postep Derm Alergol 29: 348-355.

18. Prietl B, Pliz S, Wolf M, et al. (2010): Vitamin D supplementation and regulatory $\mathrm{T}$ cells in apparently healthy subjects: vitamin D treatment for autoimmune disease? IMAJ 12: 136-139.

19. Rosenblum JL, Castro VM, Moore CE, Kaplan LM (2012): Calcium and vitamin D supplementation is associated with decreased abdominal adipose tissue in overweight and obese adults. Am J Clin Nutr 95: 101-108.

20. Małecki TM (2006): Obesity-insulin resistance - type 2 diabetes mellitus. Kardiol Pol 64: 561-566

21. Ultutas O, Taskapan H, Taskapan MT, Temel I (2013): Vitamin D deficiency, insulin resistance, serum adipokine and leptin levels in peritoneal dialysis patients. Int Urol Nephrol 45: 879-884.

22. Vaidya A, Pojoga L, Underwood PC, et al. (2011): The association of plasma resistin with dietary sodium manipulation, the renin-angiotensin-aldosterone system, and 25-hydroxyvitamin D3 in human hypertension. Clin Endocrinol 74: 294-299.

23. De Luis DA, Diaz Soto G, Conde R, et al. (2012): Relation of leptin and adiponectin with cardiovascular risk factor, intact parathormone, and vitamin D levels in patients with primary hyperparathyroditysm. J Clin Lab Anal 26: 398-402.

24. Lechnik L, Register TC, Hsu FC, et. al. (2003): Adiponectin as a novel determinant of bone mineral density and visceral fat. Bone 33: 646-651.

25. Ghamari-Langroudi M, Vella KR, et al. (2010): Cone R. D. Regulation of thyrotropin-releasing hormoneexpressing neurons in paraventricular nucleus of the hypothalamus by signals of adiposity. Mol Endocrinol 24: 2366-2381.

26. Zoair MA (2012): Role of Visfatine in Glucose and Insulin Homeostasis in Fatty Albino Rats. Nature and Science 10: 172-177.

27. García-Bailo B, Roke K, Mutch DM, et al. (2012): Association between circulating ascorbic acid, $\alpha$-tocopherol, 25-hydroxyvitamin $\mathrm{D}$, and plasma cytokine concentrations in young adults: a cross-sectional study. Nutr Metab 9: 102.

28. Szponar-Bojda A, Krasowska D, Pietrzak A, Chodorowska G (2012): Metabolic syndrome in psoriasis. Postep Derm Alergol 29: 356-362.

29. Szczawińska-Popłonyk A, Bręborowicz A (2012): Vitamin D impact on immune functions: implications for preventive strategy of allergic disease? Postep Derm Alergol 29: 176-181.

30. Moschen AR, Kaser A, Enrich B, et al. (2007): Visfatin, an adipocytokine with proinflammatory and immunomodulating properties. J Immunol 178: 1748-1758.

31. Pittas AG, Dawson-Hughes B, Van Dam RB, Li T, et al. (2006): Vitamin D and calcium intake in relation to type 2 diabetes in women. Diabetes Care 29: 650-656. 